C i e n c i a P o lít ic a 



\title{
¿Debilitamiento o fortalecimiento? Una lectura sobre la transformación del Estado en América Latina*
}

\author{
Weakening or Strengthening? A Reading about \\ the Transformation of the State in Latin America
}

Recibido: 18/12/2013

\author{
Julián Andrés Caicedo Ortiz ${ }^{* *}$ \\ Sergio Angel Baquero*** \\ Juan Carlos Rico Noguera****
}

Aprobado Evaluador Interno: 14/01/2014

Aprobado Evaluador Externo: 07/02/2014

\begin{abstract}
Resumen
Este artículo propone una lectura sobre la transformación del Estado en América Latina. Nuestra conjetura inicial parte del análisis de la relación debilitamiento y fortalecimiento del Estado como relación y aparato institucional, respectivamente. Consideramos que las dinámicas del Estado están asociadas al debilitamiento
\end{abstract}

Abstract

This article proposes a reading on the transformation of the state in Latin America. Our initial guess starts from the analysis of the relationship of weakening and strengthening of the State as relationship and Institution, respectively. We consider the dynamics of the State are associated to the weakening of the principle of social

doi:10.11144/Javeriana.PAPO19-1.dflt

* Este Artículo de Investigación hace parte del proyecto "Transformación de los sistemas en América Latina", desarrollado en el Doctorado en Ciencias Sociales, área de Relaciones de Poder y Cultura Política de la Universidad Autónoma Metropolitana, México DF, con una beca del Consejo Nacional de Ciencia y Tecnología, Conacyt 2011-2013.

** Doctor en Estudios Latinoamericanos, Universidad Nacional Autónoma de México. Candidato a Doctor en Ciencias Sociales, Universidad Autónoma Metropolitana. Investigador del Centro de Investigaciones Socio-Jurídicas de la Universidad Cooperativa de Colombia, sede Popayán. Coordinador del grupo Estado y Sociedad, de la misma universidad. Correo electrónico: julian. caicedoor@campusucc.edu.co

*** Estudiante de Doctorado en Estudios Políticos y Relaciones Internacionales de la Universidad Nacional de Colombia. Profesor de tiempo completo de la Escuela de Política y Relaciones Internacionales de la Universidad Sergio Arboleda. Miembro del Grupo de Análisis Político (G.A.P.) de la misma universidad, y del grupo de Investigación Cultura Jurídico-política, Instituciones y Globalización de la Universidad Nacional de Colombia. Correo electrónico: sergio.angel@usa.edu.co. **** Estudiante de décimo semestre de Política y Relaciones Internacionales de la Escuela de Política y Relaciones Internacionales de la Universidad Sergio Arboleda, Correo electrónico: juan89_19@hotmail.com. 


\section{Julián Andrés Caicedo Ortiz, Sergio Angel Baquero y Juan Carlos Rico Noguera}

del principio de la relación social que los fundamenta (forma-Estado), y al fortalecimiento de sus formas administrativas (aparato institucional), gracias a la intensificación del proceso de dominación y despojo característico del modelo empresarial que se adopta en la región. Concluimos que existe una lectura sistémica de la realidad social según estas transformaciones que genera diagnósticos fragmentarios de ésta, como los realizados por los informes Perspectivas de la CEPAL. Es por esto que proponemos retomar categorías como clase social y totalidad para comprender el antagonismo fundacional del Estado y los orígenes estructurales de la crisis como el orden y la condición social.

\section{Palabras clave}

América Latina; Estado; clase social; totalidad relationship (State form) and to strengthening of administrative forms (institutional unit), owed to the intensification of the process of domination and plunder which is characteristic of the business model adopted in the region. We conclude there is a systemic reading of social reality according to these changes which generates fragmentary diagnoses thereof, as the ones made by CEPAL on the Outlook reports. Therefore, we propose to return to categories such as social class and totality to understand the antagonism founding of the State and the structural origins of the crisis like social order and condition.

\section{Keywords}

Latin America; State; social class; totality 


\section{Introducción}

Coincidimos con Fernando Calderón (2004) cuando señala que el Estado en América Latina, enfrenta una crisis de legitimidad asociada a la "inercia del patrimonialismo corporativista, la aceleración de la mundialización de la economía y el divorcio entre el dinamismo de la economía y los demandas de la ciudadanía social, [...] los Estados latinoamericanos han sufrido una colonización por parte de intereses particularistas [...]" (p. 192). Esta crisis, formalmente asociada a las dinámicas del modelo de producción y acumulación de capital, ha venerado la institucionalidad pero reducido la intersubjetividad, elemento clave del otrora proyecto de Estado-nación que aportaba el carácter identitario. La crisis de legitimidad (presente) es en realidad la crisis de la forma-Estado (histórica-estructural).

Entendemos crisis como una noción de cambio abrupto y radical, como colapso, modificación o trastocamiento paulatino, crónico o cíclico, y forma-Estado como una manifestación política del mismo sistema de relaciones sociales de intercambio mercantil con orientación acumulativa. La crisis en América Latina no pertenece al modelo que se adopta transicionalmente, como uno empresarial, sino al de las formas de interacción del principio fundamental de la relación intersubjetiva debido a los incentivos que se generan, posibilitan y potencian la separación y fragmentación de los principios que fundamentan al Estado como una relación, es decir, como totalidad (Osorio, 2001).

La argumentación propuesta se centra en la reproducción de la relación debilitamiento (fracaso)-fortalecimiento (éxito). El debilitamiento de la forma-Estado como principio relacional y estructural que marca el inminente ocaso de la sociedad, y el fortalecimiento del aparato estatal, a través de reformas económicas, administrativas, políticas, etc., con la idea de generar un escenario "ideal" para la implementación sistemática de una economía de mercado que revierta el sentido de la estatalidad como totalidad y lo atomice.

En este sentido, el éxito y fracaso no son más que la idea de despojo y articulación. Como señala Gerardo Avalos (2013): "la reestructuración 'neoliberal' o 'posfordista' del capital, leída desde esta perspectiva, resulta destinada al fracaso, no ciertamente como estrategia de despojo, que en eso ha tenido un éxito rotundo, sino como programa teórico y práctico de rearticulación de la comunidad humana" (p. 6).

Adolfo Gilly y Rhina Roux (2009) señalan que la expansión de la relación de capital se sostiene en dos procesos concomitantes y entrelazados: explotación (apropiación del producto excedente bajo la forma de plusvalor) y despojo (apropiación violenta, o encubierta bajo formas legales, de bienes naturales y de bienes de propiedad comunal o pública).

David Harvey (2003) advierte sobre el despojo, planteando que no se trata de un hecho nuevo o de un retorno de la "acumulación originaria" sino de un proceso permanente que forma parte y acompaña siempre al proceso del capital. El fortalecimiento 
del aparato estatal representa el éxito del proceso de acumulación bajo esta forma, y la idea de desarrollo reemplaza para el imaginario colectivo la idea de "bien común". Como plantea Claudia Composto (2008), América Latina es una de las regiones del planeta más ricas en biodiversidad y, no casualmente, se constituye como uno de los principales destinos de privatización y mercantilización a manos de transnacionales y Estados en la nueva modalidad empresarial. Dominación, violencia, despojo y fragmentación son los pilares fundacionales del andamiaje del sistema del mundo capitalista.

Mario Magallón (2003) es muy claro al decir que la aplicación de las políticas neoliberales en América Latina no significó cohesión social ni la apropiación de la idea "necesaria" de humanidad. "El mayor problema de estos países sigue siendo la pobreza, la desigualdad social y de oportunidades, es la desigualdad en todas sus formas. De ahí la imposibilidad de asumir el credo neoliberal que limita las posibilidades de una realidad social y humana" (p. 182).

Este documento plantea una aproximación a dicha temática y ha sido estructurado dialógicamente, en cuatro momentos. En el primero se propone una descripción del proceso globalizador neoliberal a la luz de los cambios y orientaciones necesarias de los estados, enfatizando que será la forma-Estado la que colapse en el proceso de alineamiento de intereses económicos nacionales con los transnacionales, y no la idea política de la democracia procedimental o competitiva schumpeteriana ni las instituciones del aparato estatal ampliamente adaptables a la nueva lógica del capital, y es por esto que la democracia instaurada es un proceso limitado, defectivo e incompleto (Magallón, 2003).

Posteriormente, proponemos la caracterización de la crisis del Estado desde el enfoque sistémico e institucionalista, que viene a justificar el intervencionismo sistemático desde la política estableciendo nuevas categorías, no sólo para el análisis sino también para las posibles soluciones: discurso de la democracia, gobernabilidad, gobernanza, buen gobierno, gobierno de calidad, eficiencia, eficacia, calidad.

En esta línea de interpretación, señalamos que se adoptan y se implementan acciones a manera de reformas para "superar la crisis", las cuales presentan una mayor "benevolencia" al capital transnacional y no así al principio relacional que define la forma-Estado.

En este sentido, el debilitamiento es consciente y evidente, pues retomando la premisa de Margaret Thatcher "no existe esa cosa llamada sociedad". ¿Pero si no existe la sociedad tampoco existen las clases sociales?, ¿dichas categorías son simples quimeras inventadas por pensadores confundidos? (Nadal, 2013). Consideramos que no, y que dichas categorías, principalmente la de clase social, está vigente hoy más que nunca y facilita una reconstrucción teórica que permite identificar, como dicen Parra et al. (2006):

Los conjuntos abstractos y vacíos que derivan en los lugares existentes en los procesos de trabajo, los cuales varían de acuerdo al tipo de propiedad o posesión que se tenga sobre los 
medios de trabajo, al tipo de trabajo que se realiza en ese lugar: si es manual o intelectual; al control que se ejerza o no sobre el proceso productivo y a la función global que se cumple en relación al capital y al trabajo. (pp. 323-324)

Finalmente, y a modo de conclusión, se enuncian una serie de interrogantes que no han podido ser resueltos satisfactoriamente de manera disciplinaria o empírica, porque cuestionan las acciones institucionales que han volatilizado los procesos de relación social generando -indebidamente- escenarios adjetivados: políticos, sociales, económicos, culturales, ambientales. Legitimar esta "realidad" es el camino hacia el fin de la sociedad.

\section{Hacia un nuevo orden privatizado}

Las transformaciones concretas del Estado como aparato institucional y el nuevo orden internacional privatizado emergente son factores estratégicos porque fueron pensados en detrimento del entramado social, orientando acciones hacia el gobierno en aspectos esenciales de la economía global (Sassen, 2010). Se trata del alineamiento de los intereses de las burguesías nacionales con los del capital transnacional, con un adendum: al costo que sea.

Como advierte Giovanni Arrighi (2008): "a cada dominación le place esconder su nombre. Se hace necesaria entonces la precisión en el lenguaje. Aquello que se suele llamar 'modelo neoliberal' y 'globalización' es en realidad una nueva conformación mundial de la relación de capital, el nombre que se ha querido dar a una de sus periódicas mutaciones" (p. 1)

Este proceso sistemático, que reproduce la lógica del moderno sistema del mundo capitalista (Wallerstein, 1989) funciona y evoluciona según los factores económicos, desagregados inadecuadamente de la política, y de una desigualdad jerárquica de distribución basada en la concentración de ciertos tipos de producción (producción relativamente monopolizada y por lo tanto de alta rentabilidad) en ciertas zonas limitadas.

Como señala Mabel Thwaites (2008), las recientes décadas de apogeo mundial de la perspectiva y las políticas neoliberales se sostuvieron sobre dos ejes básicos: 1) el profundo cuestionamiento al tamaño que el Estado-nación había adquirido y a las funciones que había desempeñado durante el predominio de las modalidades interventorasbenefactoras; 2) la pérdida de autonomía de los Estados nacionales en el contexto del mercado mundial provocada por el proceso de globalización.

De lo que se trató fue, en primer lugar, de adoptar la lógica neoliberal con la finalidad de implementar un modelo empresarial sobre las bases de eficiencia, eficacia y calidad. En términos elementales: “éxito a cualquier costo". Y en segundo lugar, alinear los intereses del capital nacional a los del transnacional o supranacional, "vaciando" la idea de Estado-nación. Es la idea de la geografía del globo entero (Wallerstein, 1997). 
Contrario a lo que concluye Guillermo Guajardo Soto (2012) al plantear que "la privatización dejó de lado el tema central de la reforma del Estado y de las nuevas capacidades públicas, de ahí que los efectos de décadas de reformas económicas sean todavía confusos e inconsistentes” (p. 34), el fenómeno globalizador sí implicó reformas del Estado en términos administrativos y de acción pública: la tecnificación de la administración pública, eficacia y eficiencia del Estado y nuevas instituciones (Lora, 2007). Incluso, no significó una reducción del costo de burocrático como se piensa, pues la tecnificación implicó nuevas instituciones en nuevos espacios que significaron mayores y mejores salarios para la "alta burocracia" regional.

Lo que ha imperado desde entonces es el sentido privado en la acción pública: privatizaciones de sectores estratégicos y desregulaciones para generar "competitividad". Dado que el fenómeno globalizador busca consolidar un carácter y sentido supranacional, ha sido inevitable la modificación, más no desaparición, del Estado-nación desde la intersección entre soberanía y territorio. Dicho tema, según Osorio (2004), ha sido tratado de manera sobredimensionada y extrapolada para justificar una situación que puede oscilar entre lo que podríamos llamar $a$ ) el regreso a un Estado de naturaleza (sin Estado), o $b$ ) la implementación de organizaciones supranacionales que puedan ejercer adecuadamente formas de control (bloques). Nuestro planteamiento es que se dan los procesos a manera de relación y beneficio del patrón de acumulación internacional y en detrimento del orden social estatal.

La lectura neoliberal, que justificó un cambio trascendental, principalmente en América Latina porque significó abandonar el sendero de la industrialización autónoma y adoptar un modelo de desarrollo basado en la apertura económica y la competencia global (Portes, 2004), ha logrado articular paulatinamente en un mismo discurso el factor "interno", caracterizado por la acumulación de tensiones e insatisfacciones por el desempeño del Estado para brindar prestaciones básicas a la población enmarcada en su territorio, y el factor "externo", resumido en la imposición de la globalización como fenómeno que connota la ineludible subordinación de las economías domésticas a las exigencias de la economía global.

El proceso de globalización capitalista de las últimas décadas constituye un cambio importante en relación con la integración del proceso productivo mundial que impacta sobre las formas de ejercicio de soberanía estatal en cuestiones tan básicas como la reproducción material. La puja desatada entre los distintos espacios territoriales nacionales por capturar porciones cada vez más volátiles del capital global y anclarlas de manera productiva dentro de sus fronteras llevó a denominar esta etapa como la del "Estado competitivo" o "Estado de competencia" (Hirsch, 1996).

Este es el resultado de la crisis del modelo de intervención fordista y propio de la etapa neoliberal. Sin embargo, la integración a escala global no es una novedad: 
la emergencia del capitalismo como sistema mundial en el que cada parte se integra de forma diferenciada planteó desde sus orígenes una tensión entre el aspecto general (el modo de producción capitalista dominante) que comprende a cada uno de sus integrantes como piezas de un todo complejo, y el aspecto específico de cada Estado-nación particular (las formaciones económico sociales) inserto en el mercado mundial.

Como advierte John Holloway (1980), la fragmentación de lo "político" en Estados nacionales es un rasgo constitutivo del capitalismo: "la reproducción del capital a escala global tiene su contrapartida en la existencia de esos espacios estatales que la posibilitan" (p. 6o). Este proceso, como señala Joachim Hirsch (1996), refleja un Estado cuya política y estructuras internas son determinadas decisivamente por las represiones de la “competencia internacional por el lugar óptimo" (p. 80). Sus características son claras, aunque sus garantías sociales son muy pocas. Por un lado, hacer óptimas las condiciones de valoración del capital a escala nacional en relación con el proceso de acumulación globalizada en continua competencia con otros lugares óptimos nacionales; y por otro, la democratización como un proceso dinámico y complejo que siempre está amenazado de involución (Tilly, 1997) dentro de un marco institucional liberal, es decir, las decisiones políticas fundamentales desvinculadas de los procesos democráticos de formulación de voluntades y de los intereses expresados por la población. La relación entre la lucha popular y no entre las ideas de los gobernantes sostiene la (des)democratización.

Coincidiendo con Lucio Oliver (2009), los Estados latinoamericanos reformados son las formas políticas que han abierto las puertas para que el poder financiero global domine las economías nacionales, imponga una globalización unilateral y haya difundido por todos los medios la ideología y las políticas neoliberales mercantilistas.

En el desajuste que ha generado la globalización capitalista del neoliberalismo, las transformaciones del aparato estatal responden al sentido de la crisis de la forma-Estado. No se trata de una separación radical entre economía y política, entre estructuras y funciones, entre formas y sujetos, se trata de una crisis de la forma social denominada Estado.

Aunque para Karl Marx, como señala Adolfo Sánchez Vázquez (1996), el lugar teórico del Estado, del poder, de la política, responde al lugar que ocupa en él la vida real, lo político se funda en lo social, cuya anatomía es lo económico, y por eso no puede haber sino una crítica política fundada en la crítica de la economía. Pero esta relación entre lo político y lo económico en la sociedad no excluye el papel activo de la política.

Como señala Avalos (2003), desde el punto de vista metodológico el problema de la visión marxista del Estado fue siempre la concepción como entidades separadas la "economía” y la "política”, la “sociedad” y el “Estado". Frente a este problema, la teoría derivacionista trató de hallar la lógica inmanentemente política del capital. Por ende, siguiendo al autor, el Estado es una forma social, es decir, una relación social llevada al plano del pensamiento, de igual estatuto que la "forma valor", la "forma mercancía", la "forma dinero", la "forma capital". 
La forma-Estado es una manifestación política del mismo sistema de relaciones sociales de intercambio mercantil con orientación acumulativa. Las relaciones sociales capitalistas son relaciones humanas, relaciones entre seres humanos, pero se desdoblan en una esfera económica y una jurídica y política, como dos esferas no sólo diferentes sino separadas, con estructuras y legalidades propias.

Aunque la transformación de los aparatos del Estado responde a coyunturas específicas, no es debido a éstas que se ha transformado su sentido originando la crisis. Lo que se ha desahuciado es la estructura del Estado desde su funcionamiento con el modelo neoliberal, y por ende, las "recetas" se adoptan desde la modificación de la forma de la estructura. Pero la crisis de la forma-Estado no es en el sentido del modelo sino de las formas de interacción que no reconocen, incluso, la condición humana. Es la adopción de la lógica estatal de hacer morir o de dejar vivir (Foucault, 1997).

Según lo que plantea Jaime Osorio (2009), el capital constituye una unidad económica y política, y desde esa unidad se hacen presentes los fundamentos de lo estatal. Sin embargo, el propio capital establece una ruptura en dicha unidad, logrando que lo económico se presente como no político y lo político como no económico. Así pues, la "epistemología de la desconexión" y el atomismo no es otra cosa que la epistemología del capital, y no puede sino llevar a ver aquello que al capital no le molesta que se vea. En este sentido la separación es necesaria e inherente al proceso de acumulación y de alineamiento de intereses y no al fundamento intersubjetivo de la relación social (Estado).

Paradójicamente, los intereses que promueven la globalización y las neo-oligarquías que controlan los Estados, no son antagónicos sino compatibles y complementarios. De ahí su interés por implementar reformas radicales que erosionen la forma-Estado en una dirección perfectamente compatible con la normatividad internacional impulsada por la globalización en materia de los intereses del poder "central”, especulante de forma trans o supranacional.

El sentido social y político de la crisis de la forma-Estado, como plantea Antonio Negri (2003), implica un punto de ruptura definitivo con cualquier contrato social para un desarrollo planificado. Significa, incluso, que la democracia, como fue entendida en los viejos buenos tiempos, como régimen contractual tanto en sus formas liberales como socialistas, deviene obsoleta.

Por ende, se está más próximo a la institucionalización de un proceso des-democratizador que a un proceso de consolidación democrática desde la conjunción de las voluntades, esto último como fundamento del pacto (no obviamos que en la mayoría de países de la región existe una estabilidad de los sistemas, aunque ello no haya significado consolidación de una forma de democracia social).

Como bien señala John Holloway (Avalos, 2003), es necesaria la distinción entre la forma-Estado y los aparatos del Estado. La primera es una forma no autónoma de 
desarrollo de las relaciones del capital, la segunda es la forma organizacional en la que las instituciones salvaguardan y garantizan las condiciones del proceso de acumulación del capital. Es posible hablar de una “doble dimensión" del Estado, como relación de dominación capitalista y como aparato.

La forma no puede tener una existencia desencarnada, ésta se materializa a través del desarrollo institucional del Estado y la actividad de sus agentes. Similarmente, el desarrollo institucional del aparato puede solamente ser la expresión del desarrollo histórico de las relaciones sociales.

En este sentido, la idea de crisis alude ante todo a una noción de cambio que puede ser abrupto y radical, como en la noción de cambio revolucionario, o en la teoría de la crisis del capitalismo como colapso. También puede referirse a una modificación o un trastocamiento paulatino, crónico o cíclico, de los pilares básicos de una configuración social dada (Gutiérrez, 2011).

Según Marcos Kaplan (1989), el Leviatán criollo pasó por su momento más deslumbrante cuando hizo las veces de un "Estado sol” pero, como señaló Fernando Cardoso (1982), llegó a la playa desfalleciente. Sin embargo, la salida del Leviatán desfalleciente, o al menos así diagnosticado, fue "discutida" en dos sentidos: ¿̇reforma del Estado o reforma de la sociedad? Es la confusión del síntoma con la enfermedad, lo que se ha traducido en un escenario de "crisis permanente" de la forma-Estado en América Latina, y con ello el inicio de una era de servidumbre voluntaria. Para la CEPAL (2012), es la transformación del Estado para el desarrollo.

\section{La lectura institucional de la crisis del Estado}

Políticamente, la historia "oficial” de América Latina es la historia de conflictos sociales, alternativas democráticas y autoritarias en choque, interdependencia y cambios socioculturales necesarios para ser competitivos en un escenario de economía mundial. El punto de partida de la crisis del Estado responde únicamente a una razón sistémica que no es la razón estructural de la misma, y que toma fuerza en los años 80 y 90, atravesando una serie de dificultades que dejaron ver su fragilidad expresada en la incapacidad de dar respuesta eficiente ante las demandas y obligaciones del entorno. Manuel Garretón (2003) lo denominaría el agotamiento de la "matriz nacional-popular estatista" (p. 148).

Este proceso se caracterizó porque hicieron presa del Estado, estructurado bajo el modelo intervencionista, proteccionista y benefactor (Kaplan, 1989), los problemas del funcionamiento institucional: las devaluaciones, el desempleo, la constante contracción económica, la necesidad creciente de evidenciar condiciones democráticas (en algunos países inexistentes, ficticias o anómalas), el fracaso de las transiciones democráticas, la creciente violencia como referente de la dependencia y como respuesta para mitigarla. Además de esto, evidenciaron el escenario de conflicto desbordado del entramado social 
y ampliaron aún más las diferencias en las relaciones de clase, fortaleciendo la díada de ricos y pobres, con aumento desmesurado de estos últimos en relación proporcional a la acumulación, concentración y centralización del capital de los primeros. Fue una “transición simultánea” (Armijo, Bierkester, Lowenthal, 1994, p. 162).

A pesar de que no existe un acuerdo entre analistas sobre la duración y la profundidad del impacto de esta crisis global, ésta ha generado serios efectos económicos y sociales en la región que se han manifestado en las dificultades para concertar políticas que posean un carácter de Estado, es decir, que sean capaces de reflejar el conjunto de voluntades de los diversos actores en el ámbito nacional.

José Antonio Ocampo (2004), que se desempeñó como Secretario Ejecutivo de la CEPAL entre 1998 y 2002, señala que "ninguna otra región del mundo en desarrollo emprendió las reformas económicas orientadas a ampliar la esfera de acción del mercado en forma tan temprana y con tanto ‘entusiasmo’ como América Latina” (p. 17). Sin embargo, la expectativa se volvió frustración y las luces se mezclaron con sombras prominentes.

La crisis global, vista desde América Latina, no sólo ha impactado aspectos financieros. La crisis alimentaria, energética y de la violencia se hacen presentes en una sociedad que ha formalizado paulatinamente lo informal en búsqueda de la seguridad, que ha sido diluida como garantía estatal. Como indican Elmar Altvater y Birgit Mahnopf (2008): "se trata de trastocamientos del capitalismo global, de su estructura de reproducción y poder" (p. 25), es una muestra de la "nueva" cotidianeidad que vulnera el principio relacional de comunidad humana: incertidumbre, inseguridad, desprotección y vulnerabilidad.

De esta manera, los estados latinoamericanos se han redefinido desde aquello que puede denominarse como cautela y desconfianza (Fuentes, 2012), provenientes de la materialización de la inseguridad histórica, la amplitud del margen del conocimiento, la apreciación de que no todo va bien y, por supuesto, de una "sensatez" con respecto a que lo que hoy los acongoja debe ser retirado por la acción y no por el paso del tiempo. De ahí que los estados actuales sean propicios no para la estabilidad sino para la prevención; este es el nuevo argumento de la seguridad estatal desde la incertidumbre.

Este fenómeno, como señala Martín Tanaka (2005), también opacó el estudio sobre el Estado porque se implementó, por una parte, la liberalización de la economía y la reducción del papel del Estado, y por otra, desde los críticos a esas políticas, la denuncia de sus perversos efectos sociales. El tema se sustituyó por la urdimbre de la incertidumbre: "incertidumbre sobre el desarrollo y la evolución de la crisis en los distintos países de la región, sobre la velocidad y profundidad con que afectará a los distintos sectores en cada país" (Rojas, 2009, p. 130).

El proceso que enmarca esta crisis estructural refiere simbólicamente al agotamiento de un orden social y en consecuencia a uno económico y político, y a la situación de vulnerabilidad de la "matriz Estado-céntrica”, entendida como relación Estado-sociedad 
en términos alternativos del modelo de acumulación y de articulación de intereses. Es la crisis de la legitimación, de la acción social e interacción cultural (Caravozzi, 1997).

Como plantean Elmar Altvater y Birgit Mahnopf (2008), así aparece la necesidad de seguridad que no es otra que la consecuencia de las inseguridades de las interacciones humanas "que se originan por la complejidad de los problemas que deben solucionarse, y por el software de solución del que dispone el individuo" (North, 1991, p. 30). En este sentido la causa de la crisis siempre ha sido clara, pero las formas de solución, inadecuadas.

De esta forma se constituyó lo que Ruth Collier y David Collier (1991) denominarían "coyuntura crítica": un momento extremadamente fluido en el que un orden se va desmoronando progresivamente y empieza a aparecer inciertamente otro. Es una coyuntura fundamental por su plasticidad porque las estructuras están particularmente moldeables a la acción política y porque lo resultante del momento tendrá consecuencias a largo plazo.

Dicha coyuntura crítica implicó dos situaciones en la región. Por una parte, la necesidad de buscar alternativas para resolver la competitividad económica en clave neoliberal, emprendiendo transformaciones del modelo con la intención de impactar en el escenario político y en el imaginario colectivo; por otra, la pérdida de legitimidad, buscando responsabilidad en los actores políticos y no en los agentes de mercado propiamente existentes, quienes a través del discurso hegemónico garantizaban el funcionamiento de la lógica estatal.

Esta situación, asumida como circunstancial, se consensuó desde diversas "escuelas de pensamiento" (Think Tank), y por demandas crecientes de una sociedad civil que se tornaba más activa y el incumplimiento de los compromisos ante ella, inició el proceso sistemático de "recetas" o "líneas de acción" que garantizarían, "románticamente", el desarrollo social y la superación de la crisis.

Los programas aplicados han tenido un fuerte sello económico y financiero sin que se expliciten medidas equivalentes en el terreno político. Esta forma de solución de un problema global expresado localmente significó mitigar a través de políticas sociales y económicas el impacto de la crisis, buscando de manera indirecta incidir en la perspectiva democrática y lograr una mejor gobernabilidad.

La crisis que se diagnosticó señalaba problemas de gobernabilidad, agotamiento institucional y la ausencia de sistemas de partidos competitivos. Entonces inició la era de la gobernabilidad democrática: calificar y clasificar a los Estados por el grado, nivel, calidad de las instituciones y prácticas democrático-procedimentales, aunque no existan condiciones favorables para ello. ${ }^{1}$

${ }^{1}$ El Instituto del Banco Mundial (IBM) señala que las dimensiones de la gobernabilidad se integran en seis componentes, cada uno con indicadores y variables: estabilidad y ausencia de violencia; efectividad gubernamental; Calidad regulatoria; estado de Derecho; control de 
No obstante, esto último nunca fue ni ha sido un requisito para aplicar los paliativos institucionales, pues la lógica explicativa de la crisis responde a una "obviedad": "Las pérdidas que ocasionan las crisis no son recuperables en el nuevo ciclo. La próxima bonanza no asegura alcanzar, por sí misma, lo que perdamos en esta crisis. Veinticuatro años hubieron de pasar para que la región alcanzara los niveles de pobreza que exhibía antes de la crisis de 1980" (Bárcena, 2012, p. 22). Así pues, el costo social de la crisis es proyectado, inevitable, e incluso necesario. Es la idea discursiva del "sacrificio" social en favor del "bien común" del desarrollo.

La política institucionalizada se convirtió y se aceptó, por parte de los actores relevantes del sistema (neo-oligarquías e instituciones) y en gran medida por lo benevolente y bondadosa que sería para los intereses del gran capital, como el vehículo hacia el futuro del Estado. Se decretó que la crisis del Estado latinoamericano no era solamente fiscal sino de funcionamiento y legitimidad política (Lora, 2007). Identificando el problema, el software de la solución solamente debía ejecutarse.

Ante esto, la necesidad de cambios y/o reformas estructurales se impuso (Guajardo Soto, 2012). La intención fue emprender un proceso sistemático de reforma al Estado, enfocándose en un proceso complejo de liberalización económica, facilitando procesos políticos que garantizaran la eficiencia, responsabilidad y participación democrática. Estos factores, como proceso decretado, serían la salida de la crisis del Estado, de la democracia y de la gobernabilidad democrática (Rivas y Araque, 2003). Políticas económicas como desagregación de la esfera política y económica.

Pero, ¿̇la crisis del Estado fue correctamente diagnosticada desde el discurso de la democracia, la gobernabilidad, la eficiencia, la responsabilidad? ¿El problema es la "obesidad" del Estado como aparato, y la imposibilidad de ejercer control eficiente de la acción política y económica, o se debe a que el Estado burocrático perdió eficiencia y el empresarial le regresará su "esencia"?

Como señala Gerardo Avalos (2003),

Si el punto de partida es el Estado "tal y como se presenta", entonces el tema de sus transformaciones queda reducido a la descripción de los cambios que se han producido durante los últimos treinta años en esta entidad supuestamente concreta. Por lo tanto, resulta fácil, entonces, entender que las transformaciones del Estado se refieren sobre todo a las siguientes modificaciones: a) ha cambiado la función económica del Estado: de un Estado keynesiano, interventor, se ha pasado al repliegue del Estado en materia económica, lo que se ha traducido en la privatización de empresas públicas; b) como corolario de lo anterior,

la corrupción; voz y rendición de cuentas. Éstas se miden "formalmente" desde 1996. Cfr. The Worldwide Governance Indicators, 2012 Update. 
se ha pasado de un Estado extenso u obeso, a un Estado mínimo o modesto, cuya función principal se enfoca en la representación de un espacio económico doméstico frente al exterior, la defensa de ese territorio, y, sobre todo, la garantía eficiente del orden social y económico; c) todo lo anterior, ha sido acompañado por un conjunto de modificaciones en las instituciones políticas y administrativas, y en los procesos de gobierno, cuya comprensión puede ubicarse en las respuestas a las siguientes preguntas: quiénes gobiernan, cómo obtienen su legitimación y cómo gobiernan. (p. 44)

Ante esta idea de comprensión de las transformaciones del Estado, el argumento del aparato o de la "forma" del aparato del Estado, que no es igual a la forma-Estado, explora soluciones sistémicas: input-output, demandas-respuestas, y considera labor realizada los procesos de cambio organizacional y/o institucional que se traducen en indicadores y nuevos modelos eficientes de administración.

Esta orientación, que es innegable e incluso necesaria para el análisis de ciertas disciplinas residuales como la Administración Pública y la Ciencia Política, vista desde los paradigmas institucionalista y neo-institucionalista, es débil al momento de referir el sentido de la crisis del Estado de la forma en la que se construye y constituye el entramado de las relaciones sociales no diferenciadas radicalmente de lo económico y lo político, sino integradas como un Todo que en el argumento de la interpretación significa una reflexión crítica a los fenómenos de la explotación y la dominación social.

En 1985, un influyente libro de Theda Skocpol et al, anunciaba la vuelta de los estudios sobre el Estado (Bringing the State Back in); ello ocurrió en la Ciencia Política de los Estados Unidos, con el desarrollo de la escuela del nuevo institucionalismo y otras corrientes afines. En el estudio introductorio de Skocpol (1985), la autora citaba varios trabajos para ilustrar lo que consideraba una nueva ola de investigaciones sobre el Estado y, refiriéndose a América Latina, citaba los libros de Alfred Stepan (1978) sobre los gobiernos militares en Brasil y Perú, y de Ellen Trimberger (1977) sobre las Fuerzas Armadas y los Estados en Japón, Turquía, Egipto y Perú. De lo que se trataba era de considerar al Estado como variable independiente para explicar fenómenos políticos, rescatar la autonomía y lo que hoy llamaríamos “capacidad de agencia” del campo del Estado y las instituciones, y no verlos como mera manifestación de factores sociales, como ha sido usanza desde tradiciones estructuralistas. (2005, Tanaka, p. 92)

Como refieren Adolfo Gilly y Rhina Roux (2009) citando a Husson:

La característica principal del capitalismo mundializado es el descenso de la parte salarial, es decir, de la parte del PIB que absorben los asalariados. Esa tendencia equivale, en términos marxistas, a una elevación de la tasa de explotación. Se trata de un resultado 
sólidamente establecido sobre datos estadísticos indiscutibles y que se aplica a la mayoría de países, tanto del Norte como del Sur. (p. 4)

Por lo tanto, tirar por la borda las interpretaciones que vinculan el universo de lo político estatal con los diversos procesos de la dominación social sería, como señala Avalos (2003), si en la teoría, en el nivel de lo racional o de lo consciente, no se quisiera reconocer por incómoda o molesta una experiencia traumática que no obstante sigue existiendo. "Desalojo" o "represión" fue el nombre técnico que Freud (1908) le dio a este fenómeno psíquico. Convenientemente llevado al plano social y político, puede hablarse de una sintomática represión de un vínculo traumático: el que mantiene, de forma constitutiva y "siempre-ya”, la economía y la política.

Pero ¿qué ocurre cuando existe un desmantelamiento sistemático de la lógica estatal y se acepta? En ese momento se incorpora en la cotidianeidad relacional y social un diagnóstico débil y superficial que le significará una “privación”, la cual no es más que una "nueva" forma de castigo no-institucionalizado. Por eso la acepta políticamente, a manera de nuevas formas de cesarismo, bonapartismo o bismarckismo (Kaplan, 2001). La implementación del autoritarismo democrático caudillezco es necesaria y progresiva si garantiza el proceso de alineamiento de intereses de la desahuciada economía local y nacional con el capital transnacional, y regresiva si la política imposibilita dicho vínculo y emplea los recursos estatales para inversión y gasto social con políticas asistencialistas.

No se trata de una simple paráfrasis del "ellos saben muy bien lo que hacen, pero aun así lo hacen” (Sloterdijk, 1989, p. 786) porque al interpretar el sentido que asume el entramado social y relacional como depositario de las "acciones" reformistas estatales, es evidente que existe una necesidad por estructurar la propia realidad social que se logra a través de la ilusión pero no consigue enmascarar el estado real de las cosas. De ahí que su función no sea otra que ofrecer un punto de fuga de la realidad. Es la realidad social misma como una huida de algún núcleo traumático, es la ilusión de lo real. Por eso, "ellos saben que en su actividad, siguen una ilusión, pero aun así lo hacen” (Zizek, 1992, p. 57).

De forma complementaria, el sentido de las "recetas" contra la crisis del Estado podría expresarse a través de lo señalado por Zizek (1992) quien, refiriéndose a Lacan, menciona que fue éste quien evidenció el gran logro de Marx: "demostrar que todos los fenómenos que a la conciencia burguesa cotidiana le parecen simples desviaciones, deformaciones contingentes y degeneraciones del funcionamiento "anormal" de la sociedad (crisis económicas, guerras y demás), son abolibles mediante el mejoramiento del sistema” (p. 175). Analógicamente, lo que para Freud sería el funcionamiento de la mente humana (los sueños, los lapsus y fenómenos anormales similares) son las reformas para el modelo de apropiación neoliberal, productos necesarios del sistema y la fuente de la crisis de la forma-Estado. Las reformas son causa y no consecuencia. 


\section{¿La superación de la crisis de Estado?}

El Estado es un asunto clave para la comprensión de las dinámicas políticas, económicas y sociales en América Latina. No sólo como aparato sino como proceso relacional que permite superar el límite del paradigma de las transiciones y la consolidación y los límites de la temática propuesta por el Consenso de Washington (Tanaka, 2005).

Como hipótesis, Lucio Oliver (2009), plantea que:

La crisis del Estado, no implica la antesala de grandes reformas, de una revolución o de un nuevo estadio histórico, sino que podría bien ser eso u otra cosa, por ejemplo, una reformulación regresiva del papel histórico del Estado en América Latina, reformulación que redefine lo nacional y lo popular como base del Estado, pero restringiéndolo, tal como aconteció con los Estados oligárquicos del siglo XIX. (p. 58)

Sin embargo, la transformación del Estado para el desarrollo, y en ello la formaEstado, no le otorga del todo la razón. La crisis del Estado significó, con elementos democráticos y reaccionarios (democracias autoritarias), y desde una reformulación regresiva del papel del Estado, la implementación de una ola de reformas que buscaron "resolver" el problema sustantivo de la región, identificado como político pero "resuelto" desde lo económico: gobernabilidad democrática (Crozier, 1975).

Pero no es un problema de gobernabilidad el que ha llevado al uso del calificativo de Estados “débiles", “inviables”, "fracasados” o "fallidos”, adjetivación alimentada desde los intereses estratégicos del gran capital incluso a manera de sofismas de distracción, sino de las formas en las que se ha desenvuelto el proceso relacional de la política y el capital.

Esa es la interconexión entre el capital, entendido como forma social, y el universo de lo político, que no significa una vinculación mecánica entre dos objetos diferentes, sino una compleja relación en el interior de una misma forma social (Avalos, 2003). Es en las paradojas de la globalización donde se advierte el interés de fragmentar el entramado social proyectando realidades adjetivadas: económica, política, social, y de ahí el sentido de las reformas.

Para consolidar este "error", seguramente de manera consciente, se desplazó el sentido de la teoría y filosofía política en la apropiación interpretativa de la crisis, y se recurrió a las formas simplificadas de la acción política-estatal. Es decir, se generó un advenimiento a la lógica de las reformas, las cuales se presentarían genéricamente en dos órdenes. En el primero, las reformas económicas, denominadas inicialmente de "primera generación", que persiguieron los objetivos del Consenso de Washington: eliminar o simplificar la intervención del Estado, acelerar el crecimiento y contribuir a lograr otros objetivos de desarrollo. 
La adopción de estas reformas en los años ochenta fue directamente sobre el modelo económico y la racionalidad del mismo, buscando estabilización y desregulación. Se caracterizaron por una desestimación del sistema político, considerando incluso que la democracia como sistema era costosa e inversamente proporcional al desarrollo económico, por lo que muchas de éstas se estimularon y adelantaron con el claro soporte de sistemas abiertamente autoritarios (Payne, 1999).

Las prioridades de los reformadores durante este periodo fueron la reducción del tamaño del aparato Estado y la eliminación o transferencia a otros niveles de gobierno o al sector privado de los servicios prestados por el sector público para generar ahorro fiscal. Las herramientas "pertinentes" fueron la descentralización, la privatización, la desregulación de la economía y la tercerización de servicios públicos, con el fin último de eliminar patrones culturales disfuncionales para la economía de mercado como el clientelismo, paternalismo e intervencionismo, mismos que, sobra decir, lejos de desaparecer lograron articularse a la nueva lógica estatal y adquirir nuevas formas instrumentales (Caicedo, 2008).

Pero en los años noventa, como refiere Brito, al inventariarse los resultados de la estrategia de desarrollo y de las reformas adelantadas en la década anterior, es decir, ante una revisión "crítica" del Consenso de Washington, fue evidente que los costos en términos de inequidad y dualización social fueron mayores que sus beneficios, en tanto a crecimiento, estabilidad económica y eficiencia pública (Brito, 2003). Así inicia el replanteamiento de la actuación del Estado y de los gobiernos, y con ellos América Latina ingresa en la siguiente etapa de las reformas: "las de segunda generación", las institucionales. Entonces el diagnóstico se mantuvo en el mismo sentido.

Estas reformas, que refieren a un orden político, judicial y de la administración pública, se "difundieron" como las coadyuvantes a las metas estipuladas por los organismos económicos. Sin embargo, por su naturaleza implicaron mayor complejidad, pues eran más inciertas y más difíciles de implementar. Por consiguiente, sus posibilidades de éxito dependieron no sólo de la consistencia y el refinamiento de sus detalles técnicos sino de si el proceso político para aprobarlas e implementarlas era conducente a soluciones, que aunque técnicamente no fueran las óptimas, proyectaran estabilidad, adaptabilidad, coherencia y, sobre todo, interés público. El problema de la crisis se ubicaría entonces sobre la idea de la voluntad política.

Las nuevas propuestas complementarían lo que había quedado pendiente: estabilización macroeconómica y confrontación de los estilos tradicionales de administrar lo público. Con variantes significativas con respecto a los instrumentos y objetivos del cambio, se incluyen el desarrollo institucional y una radical modernización gerencial de la administración pública, además del "perfeccionamiento" del sistema político democrático. El objetivo fue "refinar" las reformas económicas desde diversos ámbitos, por lo 
cual se inician procesos de reformas presupuestales, tributarias, de política industrial, social y del sistema educativo (Ramírez, 2009).

No obstante, estas acciones se encaminaron a un debilitamiento y fortalecimiento del Estado: debilitamiento (fracaso) de la forma-Estado, y fortalecimiento (éxito) del aparato institucional. La globalización generó una "paradoja del poder del Estado" porque fue capaz de adelantar aquellas estrategias que podrían aliviar la crisis en la cual se hallaba inmerso a manera de consenso entre los factores de legitimidad externos e internos, como ofrecer las bases para una nueva estrategia económica y política en un momento en el que los modelos de desarrollo estaban agotados (Philips, 1983). Las reformas adoptadas fueron puestas al servicio del capital transnacional, como base social para la reestructuración global del capitalismo (Robinson, 2001). El desmantelamiento de la forma-Estado fue, entonces, necesaria.

Por otra parte, los indicadores de impacto de las reformas desde finales de los noventa han intentado proyectar la idea de que el camino implementado es el correcto en términos de mejores garantías y condiciones sociales; sin embargo, lo referido es tan solo una paradoja más de la lógica del proceso de acumulación y una consecuencia del mismo.

Tomemos un indicador: la pobreza y marginación en la región. Según datos del informe Panorama Social de América Latina de la CEPAL (2012), para el 2011 el porcentaje de pobreza y marginación en la región fue de $29.4 \%$, con una tendencia a la baja de 1.8\% anual, según proyecciones desde el 2002. Sin embargo, estos datos contrastan con la situación social y laboral en la región.

El mismo informe advierte, entre líneas, la preocupación de que la principal vía para salir de la pobreza formalmente se haya agotado:

El empleo remunerado es una de las principales vías para salir de la pobreza, pero la mayoría de las personas pobres y vulnerables (de 15 años y más) ya se encuentran ocupadas. Los desocupados representan solo alrededor de un $8 \%$ entre los indigentes y un 6\% entre los pobres no indigentes. Esto de nuevo evidencia una situación persistente en la región, derivada de la heterogeneidad de su estructura productiva, y es que cualquier tipo de empleo remunerado no es garantía de superación de pobreza. (Las cursivas son nuestras). (p. 15)

¿Entonces cuál es el camino? Como señalan Altvater y Mahnkopf (2008), ¿el trabajo negro, el dinero sucio y la política informal?

Por otra parte, la relación desigualdad y desconfianza que complementa la triada analizada por la CEPAL tampoco arroja resultados y expectativas óptimas, pues concluye que uno de los grandes desafíos que continúa enfrentando América Latina es la reducción de los elevados niveles de desigualdad en la distribución del ingreso. En la mayoría de los países se observa que un conjunto reducido de la población acumula una gran proporción de todos los ingresos generados, mientras que los más pobres sólo alcanzan a recibir una escasa porción. 
Según el coeficiente de Gini, que mide la desigualdad, en la región es de o,51, nivel de desigualdad sustancialmente más alto que otras regiones del mundo, teniendo en cuenta que Estados Unidos tiene 0.378 y los países de la OCDE 0.313. De ahí que el promedio simple de los valores en América Latina indique que el 10\% más rico de la población recibe el $32 \%$ de los ingresos totales, mientras que el $40 \%$ más pobre recibe el 15\%. Entre 1997 y 2011, tanto la percepción de injusticia distributiva como la desconfianza en las instituciones (poder legislativo, el poder judicial y los partidos políticos), se asociaron con el coeficiente de Gini. Es claro que donde existe una desigualdad objetiva en la distribución del ingreso se aprecia una mayor percepción de injusticia distributiva y una mayor desconfianza institucional (CEPAL, 2012).

De la misma forma, Alicia Bárcena (2012) señala que en América Latina son necesarios procesos de reordenamiento institucional, comercial y estructural, aún más severos que los iniciados a finales del siglo XX, para de esta forma "ofrecer" una estructura productiva y exportadora basada en ventajas comparativas estáticas, en muchos casos (en América del Sur) vinculadas a los recursos naturales, y en otros, relacionadas con salarios bajos, manufacturas intensivas en mano de obra o servicios. Además, todavía existen muy pocas ventajas competitivas dinámicas, hay baja inversión y rezagos en innovación, ciencia y tecnología, educación e infraestructura, informalidad del mercado de trabajo, un alto costo de la violencia (7,7\% del PIB en Centroamérica), y vulnerabilidad asimétrica al cambio climático.

¿Esta es la idea de la transformación del Estado para el desarrollo? No. La transformación del Estado en América Latina significa entonces el inicio de un conflicto generado por la mundialización del capital dentro y fuera del espacio institucionalizado. Lo que referimos no es lo que imposibilita el desarrollo, son las consecuencias del proyecto de desarrollo globalizador. El fortalecimiento (éxito) institucional bajo la premisa de incrementar los niveles de apropiación y producción del capital contrasta con el debilitamiento (fracaso) de las garantías sociales que política y económicamente, y de manera complementaria, habían sido las garantes del pacto social.

La realidad no es una crisis económica, una crisis política, una crisis del Estado, una crisis de la democracia formal, que responde a momentos, circunstancias e intereses diferentes, como señala Prada (2008). La crisis de la forma-Estado es la crisis del proceso relacional, “es la segunda segunda muerte de Leviatán, aquella que aniquila al Estado como unión de los hombres en una condición que supera al estado de naturaleza donde la vida es breve, insegura e infeliz" (Avalos, 2013, p. 177).

\section{A manera de conclusión}

La historia reciente de América Latina es, entonces, la historia de las reformas. Pero ¿qué se modificó? ¿Se logró configurar un Estado, como aparato estable, inclusivo, 
incluyente, eficaz, medianamente democrático? ¿Las relaciones sociales que definen la forma-Estado, lograron una armonización? ¿Los agentes de mercado no se asumen como sociedad civil y viceversa? Si estos interrogantes y los muchos más que se pueden y deben de recogerse, desde la filosofía y la teoría política, mal llamada heurística, están resueltos y pueden ser sostenibles desde el discurso y la acción de las reformas, estamos ante un nuevo sentido de la forma-Estado. Pero como estos procesos han sido "cosméticos", la interpretación y discusión de lo que implica la crisis de la forma-Estado está vigente y va más allá de la comprensión del límite estructural que determina la existencia de todo Estado como aparato de dominación.

Como señala Mabel Thwaites (2008), la "nueva literatura" (el entrecomillado es nuestro), sobre los cambios que ha impuesto la propia dinámica del capitalismo global a la definición de los "espacios" sobre los cuales se ejerce la soberanía atribuida al Estado-nación, aporta una interesante perspectiva referida al proceso de globalización y su impacto tempo-espacial; sin embargo, se focaliza en el análisis de los espacios estatales del centro capitalista, muy especialmente en Europa.

Es así que muchos de los rasgos que son leídos como novedad histórica para el caso de los Estados nacionales europeos (en cuanto a la pérdida relativa de autonomía para fijar reglas a la acumulación capitalista en su espacio territorial, comparada con la etapa interventora-benefactora) no lo son en la periferia.

El problema de estos diagnósticos, está en la coherencia lógica interna y en la solvencia académica, aceptada por una comunidad institucionalizada en diversas escuelas de pensamiento, como señalamos, que buscan explicar y dar cuenta de la realidad y construir nuevos "sentidos comunes" capaces de guiar y/o legitimar cursos de acción que puedan tener un impacto efectivo en la realidad que metodológicamente se pretenda modelar.

Por esto es necesario reconstruir para el futuro herramientas metodológicas y categorías que permitan descifrar la política como antagonismo y las razones de la interacción y orden social, no como posibilidad, sino como mecanismos de superación y transformación. La categoría de clase social y de totalidad permite hacer frente crítico a esta orientación neo-institucionalista o de elección racional, que prima por el individuo y no el sujeto. La realidad latinoamericana como posibilidad aún se expresa y puede expresarse en términos del Gran Meta Relato, de una posibilidad de transformación.

\section{Referencias Bibliográficas}

Altvater, E. y Mahnopf, B. (2008). La globalización de la inseguridad. Trabajo en negro, dinero sucio y política informal. Buenos Aires: Paidós.

Armijo, L. Biersteker, T. y Lowenthal, A. (1994). The Problem of Simultaneous transitions. Journal of Democracy, 5(4), 161-175. 
Avalos, G. (2003). "Las dimensiones políticas del capital y las transformaciones del Estado”. En: R. García Jurado y J. Flores. (Coords.), La democracia y los ciudadanos (pp. 43-68). México: UAM-X.

Avalos, G. (2013). La cuestión del Estado en la reorganización del capital. El Cotidiano, $177,5-16$.

Bárcena, A. (2012). Panorama Económico y Social de América Latina y el Caribe. La perspectiva de la CEPAL. Santiago: CEPAL.

Brito, M. (2003). Las reformas de "segunda generación" en América Latina. La reivindicación de la política”. Ciencias de Gobierno, 13, 11-35.

Caicedo, J. (2008). Democracia, nación y sociedad. La crisis del bipartidismo en Colombia. Latinoamérica, Revista de Estudios Latinoamericanos, 46, 9-39.

Calderón, F. (2004). Notas sobre la crisis de legitimidad del Estado y la democracia. En: D. Caputo (Dir.), La democracia en América Latina. Hacia una democracia de ciudadanos y ciudadanas (pp. 192-213). Buenos Aires: PNUD-Altea.

Cardoso, F. (1982). Reflexiones sobre la estructura social y política de los países más industrializados de América Latina. En: F. Cardoso, R. Prebisch, y R. Green. (Coords), En torno al Estado y el desarrollo (pp. 133-282). México: Ed. Nueva Imagen.

Cavarozzi, M. (1997). Autoritarismo y democracia (1955-1966). La transición del Estado al mercado en Argentina. Buenos Aires: Ariel.

CEPAL (2012). Panorama Social de América Latina. Disponible en: http://www.eclac. org/publicaciones/xml/5/48455/PanoramaSocial2012DocI-Rev.pdf

Collier, R. y Collier, D. (1991). Shaping the Political Arena. New Jersey: Princeton University Press.

Composto, C. (2008). Acumulación por despojo y neoextractivismo en América Latina. Una reflexión crítica acerca del estado y los movimientos socio-ambientales en el nuevo siglo. Astrolabio, 8, 323-352.

Crozier, M., Huntington, S., Watanuki, J. (1975). The crisis of democracy. Report on the governability of democracies to the Trilateral Comission. New York: New York University Press.

Foucault, M. (1997). Defender la sociedad. México: Fondo de Cultura Económica.

Freud, S. (1908). Teorías sexuales infantiles. Disponible en: http://www.biblioteca. org.ar/libros/211796.pdf.

Fuentes, E. (2012). El ocaso del Estado moderno. Bogotá: Universidad Jorge Tadeo Lozano. 
Garretón, M. (2003). Latin America in the Twenty-First Century: Toward a New Sociopolitical Matrix. Boulder: Lynne Rienner Publishers.

Gilly, A y Roux, R. (2009). Capitales, tecnologías y mundos de la vida. El despojo de los cuatro elementos. Herramienta, 40. Disponible en http://www.herramienta.com.ar/ foro-capitalismo-en-trance/capitales-tecnologias-y-mundos-de-la-vida-el-despojode-los-cuatro-elemen.

Guajardo Soto, G. (2012). América Latina: ¿̇zona mixta o continente perdido en las últimas cuatro décadas? Latinoamérica. Revista de Estudios Latinoamericanos, 55, 9-34.

Gutiérrez, R. (2011). Sobre la crisis del Estado mexicano. Globalización. Revista de Economía, Sociedad y Cultura. Disponible en: http://rcci.net/globalizacion/2011/ fg1214.htm.

Harvey, D. (2003). El nuevo imperialismo. Madrid: Akal.

Hirsch, J. (1996). Globalización, Capital y Estado. México: UAM-X.

Holloway, J. (1980). "Debates recientes sobre el Estado en Gran Bretaña y Alemania Occidental”. En: M. Archila (Coord), Del Estado Instrumento a la Forma-Estado (pp. 57-72). Bogotá: Centro de Investigación y Educación Popular.

Kaplan, M. (1989). Estado y sociedad en América Latina. México: Oasis.

Kaplan, M. (2001). Neocesarismo y constitucionalismo, México: IIJ-UNAM.

Lora, E. (2007). La reforma del Estado en América Latina: una revolución silenciosa”. En:

E. Lora (Ed.), El estado de las reformas del Estado en América Latina. Chile: BID.

Magallón, M. (2003). La democracia en América Latina. México: CISALC-Plaza y Valdés.

Nadal, A. (2013). Thatcher y Hayek: la sociedad no existe. México: UNAM.

Negri, A. (2003). La forma Estado. Madrid: Akal.

North, D. (1991). Institutions. Journal of Economic Perspectives, 5(1), 97-112.

Ocampo, J. (2004). Reconstruir el futuro. Globalización, desarrollo y democracia en América Latina. Bogotá: CEPAL-Norma.

Oliver, L. (2009). "Conflictos y tensiones en torno del Estado ampliado en América Latina”. En: M. Favela y D. Guillén (Coords.). América Latina. Los derechos y las prácticas ciudadanas (pp. 51-79). Buenos Aires: CLACSO Libros

Osorio, J. (2001). Fundamentos del análisis social: la realidad social y su conocimiento. México: FCE. 
Osorio, J. (2009). Estado, biopoder y exclusión. Análisis desde la lógica del capital. Barcelona: Anthropos-UAM.

Osorio, J. (2004). Crítica de la economía vulgar: Reproducción del capital y dependencia. México: Porrúa.

Parra, J. et Al. (2006). Clase-categoría: una operacionalización del concepto marxista de clase social. Revista de Ciencias Sociales, 12(2), 319-331.

Payne, M. (1999). Instituciones políticas e instituciones económicas: nueva visión sobre las relaciones entre el Estado y el mercado. Reforma y Democracia, 13, 117-140.

Philips, N. (1983). Globalization and the paradox of the State Power: perspectives from Latin America, Coventry: University of Warwick.

Portes, A. (2004). El desarrollo futuro de América Latina. Neoliberalismo, clases sociales y transnacionalismo. Bogotá: ILSA.

Prada, R. (2008). Entrevista en el documental boliviano El estado de las cosas.

Ramírez, M. (2009). Las reformas del Estado y la administración pública en América Latina y los intentos de aplicación del New Public Management. Estudios Políticos, 34, 115-141.

Rivas, J., Araque, J. (2003). El Estado en América Latina: crisis y reformas. Espacio Abierto, 12 (о03), 417-435.

Robinson, W. (2001). Social Theory and Globalization: The rise of a Transnational State. Theory and Society, 2 (30), 157-200.

Rojas, F. (2009). Siete efectos políticos de la crisis internacional en América Latina. Nueva Sociedad, 224, 128-143.

Sánchez Vázquez, A. (1996). La cuestión del poder en Marx. En: Avalos, G. y París, M. D. (Coords.). Política y Estado en el pensamiento moderno (pp. 163-179). México: UAM.

Sassen, S. (2010). Territorio, autoridad y derechos. De los ensamblajes medievales a los ensamblajes globales. Buenos Aires: Katz editores.

Sloterdijk, P. (1989). Crítica de la razón cínica. Madrid: Taurus.

Tanaka, M. (2005). El regreso del Estado y los desafíos de la democracia. En: Vich, V. (Ed.). El Estado está de vuelta: desigualdad, diversidad y democracia (pp. 91-110). Lima: Instituto de Estudios Peruanos.

Thwaites, M. (2008). ¿Qué Estado tras el experimento neoliberal?, Reforma y Democracia, 41, 1-12. 
Tilly, C. (1997). Democracy. Nueva York: Cambridge University Press.

Wallerstein, I. (1989). The modern world-system III: The second era of great expansion of the capitalist world economy. Nueva York: Academic Press.

Wallerstein, I. (1997). States? Sovereignty? The Dilemma of Capitalists in an Age of Transition. Irvine: University of California. Disponible en http://www2.binghamton.edu/fbc/archive/iwsovty.htm

Zizek, S. (1992). El sublime objeto de la ideología. México: Siglo XXI Editores. 
